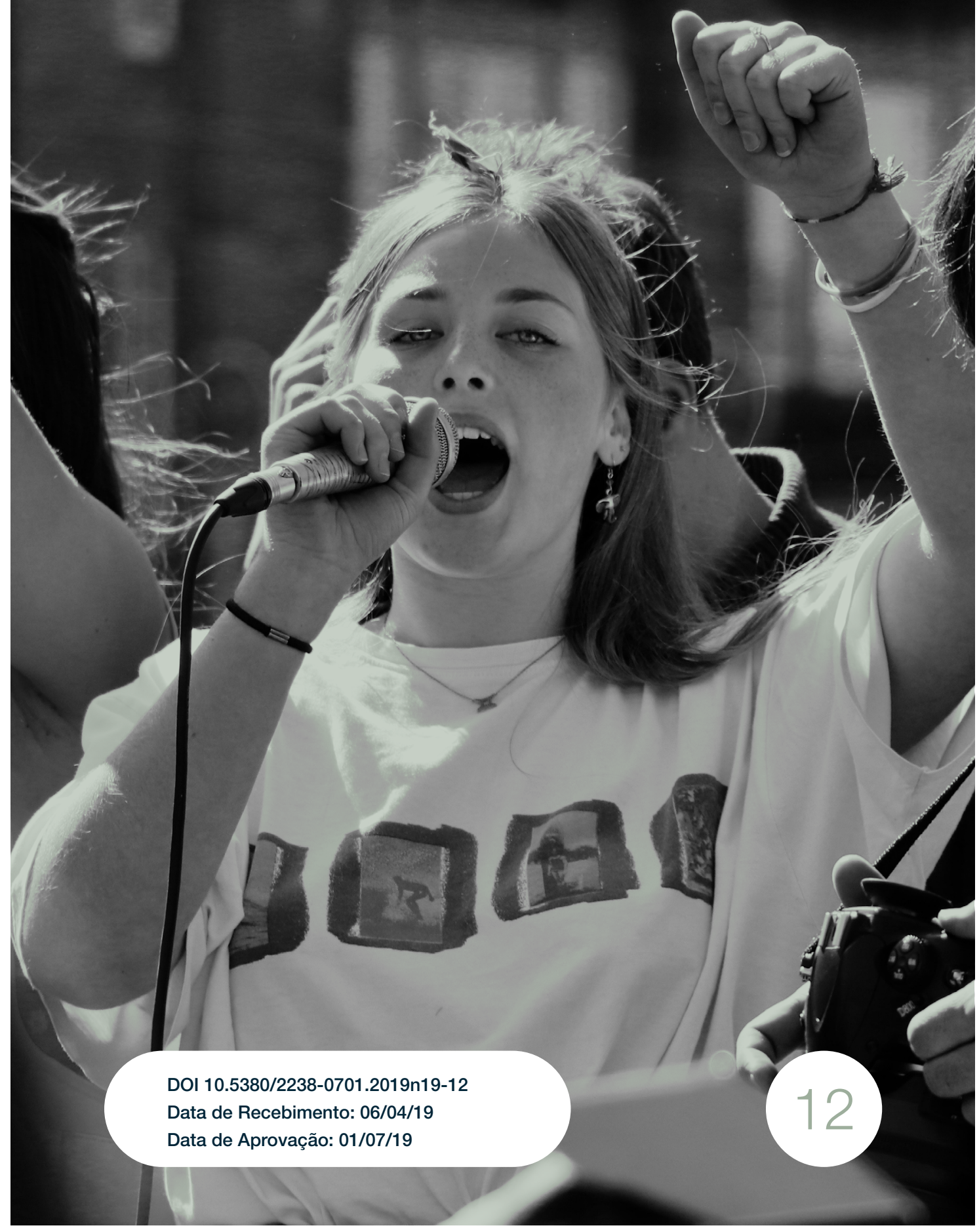


Michel Temer: do vazamento de um discurso à posse do governo interino 


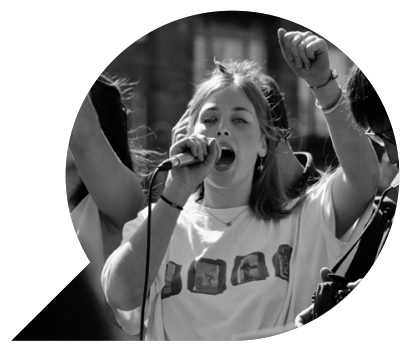

\title{
Michel Temer: Do vazamento de um discurso à posse do governo interino ${ }^{1}$
}

\author{
Michel Temer: Del fugamiento de un discurso a la \\ posesión del gobierno interino \\ Michel Temer: From a leaked speech to the interim \\ government
}

PEDRO CHAPAVAL PIMENTEL ${ }^{2}$

BRUNO WASHINGTON NICHOLS ${ }^{3}$

JOSEMARI POERSCHKE DE QUEVEDO ${ }^{4}$

Resumo: Recentes pesquisas sobre o impeachment de Dilma Rousseff enfatizam o papel de diferentes atores políticos. Entretanto, é escassa a comparação da construção discursiva pré e pós-impeachment. Este artigo analisa um áudio vazado à imprensa e o discurso de posse de Michel Temer. Foi verificado e o áudio vazado pode ser visto como prévia do discurso de posse e se os recursos retóricos variaram. A Análise de Conteúdo toma como base Panke e

1 Este trabalho decorre de uma versão preliminar apresentada no VII Congresso da Associação Brasileira de Pesquisadores em Comunicação e Política (VII Compolítica), na Universidade Federal do Rio Grande do Sul (UFRGS), em maio de 2017.

2 Professor substituto do Departamento de Comunicação da Universidade Federal do Paraná. Doutorando em Administração (PPGADM-UFPR) e mestre em Comunicação (PPGCOM-UFPR). Membro do Grupo de Pesquisa Comunicação Eleitoral da UFPR. E-mail: professorchapaval@gmail.com.

3 Doutorando em Ciência Política (PPGCP-UFPR) e mestre em Comunicação (PPGCOM-UFPR). Membro dos grupos de pesquisa Comunicação Eleitoral e COMPA. E-mail: bru.nichols@gmail.com.

4 Doutora em Políticas Públicas pela UFPR e Mestre pelo Programa de Pós-Graduação em Comunicação e Informação da UFRGS (2010). E-mail: josemari.quevedo@gmail.com. 
Cervi (2011). Os temas mais recorrentes em ambos discursos foram "Político institucional" e "Administração pública". Observou-se também o uso de técnicas argumentativas visando a persuasão para a governabilidade.

Palavras-chave: Discurso político; Impeachment; Dilma Rousseff; Michel Temer; Governabilidade.

Resumen: Investigaciones sobre el impeachment de Rousseff enfatizan el papel de diferentes actores políticos. Sin embargo, la comparación de la construcción discursiva pre y post-impeachment es escasa. El artículo analiza un audio filtrado a la prensa y el discurso de posesión de Michel Temer. Se verificó si el audio filtrado puede ser visto como previo del discurso de posesión y si los recursos retóricos variaron. El Análisis de Contenido toma como base el trabajo de Panke y Cervi (2011). Los temas más utilizados en ambos discursos fueron "Político institucional" y "Administración pública". Se observó también el uso de técnicas argumentativas visando la persuasión para la gobernabilidad.

Palabras clave: Discurso Político; Juicio Político; Dilma Rousseff; Michel Temer; Gobernancia.

Abstract: Researches on the impeachment of Dilma Rousseff emphasise the role of different political actors. However, there are few studies comparing the discursive construction before and after the impeachment. The article analyses an audio leaked to the press and the inaugural speech. It was verified whether the leaked speech can be understood as a preview of the inaugural one and whether the rhetoric resources used to build the speeches varied. The Content Analysis carried is based on Panke and Cervi (2011). The most recurrent themes were "Institutional politics" and "Public administration". It was also observed the strategic use of argumentative techniques to persuade about Temer's governability.

Keywords: Political speech; Impeachment; Dilma Rousseff; Michel Temer; Governability. 


\section{Introdução}

Pesquisas que avaliam o processo de impeachment de Dilma Rousseff enfatizam o papel de atores políticos, caso da imprensa (ALMEIDA; LIMA, 2016; MARQUES; MONT'ALVERNE; MITOZO, 2017); do empresariado (BRAGA; MONTROSE, 2017); das mídias sociais (FREITAS; FRANÇA, 2017); do Poder Legislativo (DUARTE, 2017); e do Poder Judiciário (NAPOLITANO, 2017). Há estudos que avaliam os discursos de atores diretamente envolvidos no processo: a então presidente Dilma Rousseff e o vice-presidente Michel Temer (COIMBRA, 2017; IACOMINI JUNIOR, CARDOSO, PRADO JUNIOR, 2018). Entretanto, são escassos os trabalhos que comparam a construção discursiva entre os contextos pré e pós-impeachment.

Este artigo analisa dois discursos de Michel Temer (MDB) $)^{5}$ que pavimentaram o caminho para a instauração de um governo de transição, decorrente do processo de impeachment de Dilma Rousseff (PT). O primeiro discurso veio a público em 11 de abril de 2016 com o vazamento de um áudio de 13 minutos e 53 segundos compartilhado pelo aplicativo WhatsApp, isso é, na data da aprovação do parecer pela abertura do processo de afastamento de Rousseff na Câmara dos Deputados. $O$ segundo discurso foi proferido na posse como presidente interino - em 12 de maio de 2016 - após a confirmação do afastamento de Rousseff.

Considerando a forma em que Temer assumiu a Presidência, os discursos podem ser vistos como "um conjunto de estratégias desenvolvidas por um político ou partido para influenciar a opinião pública sobre programas de governo, projetos de lei, ideias partidárias" (PANKE, 2010, p. 2). Dessa forma, em que medida haveria semelhanças e particularidades entre os discursos? Seria possível verificar semelhanças quanto aos apelos retóricos utilizados?

Visando responder essas perguntas, os objetivos desse trabalho são analisar quanto e como os dois discursos se aproximam e se distanciam. A Análise de Conteúdo aplicada nesse estudo parte da proposta elaborada por Panke e Cervi (2011) e utilizada pelo grupo de pesquisa Comunicação Eleitoral do Programa de Pós-Graduação em Comunicação da Universidade Federal do Paraná (CEL-UFPR). Levantaram-se duas

5 À época, o Movimento Democrático Brasileiro ainda era chamado por Partido do Movimento Democrático Brasileiro (PMDB). A mudança se deu em fins de 2017. 
premissas para a análise: (1) o áudio do WhatsApp pode ser interpretado como uma prévia do discurso de posse proferido por Michel Temer; e (2) os recursos retóricos utilizados para construir os discursos variaram conforme a conjuntura.

O artigo se divide em cinco seções, incluindo essa introdução. A seção seguinte apresenta os eixos teóricos que conduzem esse trabalho. Na seção três, a estratégia metodológica, baseada na categorização de discursos políticos, é explicada e integrada de análises quantitativas descritivas e qualitativas para avaliar ambos os discursos. As fontes de informação são documentais e consistiram na transcrição do áudio vazado e na transcrição oficial do discurso de posse de Temer. A seção quatro aponta e cruza os principais resultados. Por fim, na seção cinco são tecidas as considerações finais.

\section{Discursos e governabilidade}

A governabilidade se liga às relações entre Estado e o funcionamento da sociedade. Em que pese os discursos serem peças-chave na comunicação política, não basta para se ter uma boa avaliação pública ou que o sujeito político apenas discurse ou se apresente bem. As mudanças ocorridas na sociedade em decorrência da maior visibilidade gerada, em parte pelo avanço tecnológico, fizeram com que o aumento na velocidade e o vazamento de notícias se tornassem elementos intrínsecos às disputas políticas. Uma vez que o sistema político compreendeu a relação entre desenvolvimento tecnológico e poder, ele passou a buscar "através das tecnologias prolongar o seu poder no tempo" (TOMÉ, 2017, p. 305-306).

Governos podem ser arruinados por mudanças e subsequente apreciações das pessoas, e a fim de evitar essa ruína, emerge o conceito da governabilidade, referente a três vetores: (i) a capacidade de o Estado financiar suas atividades; (ii) a "capacidade dos atores e organizações do sistema político de produzir e manter a lealdade" dos cidadãos; e (iii) a capacidade do Estado de conduzir os processos de implementação de políticas públicas (TORRES, 2016, p. 153).

Na complexidade da máquina governamental, segue o mesmo autor, os conceitos de governabilidade e governança se aproximam ao en- 
volverem dimensões fiscais, de legitimidade e de administração. Grosso modo, a governabilidade condiz à capacidade do Estado em resolver os problemas colocados pela sociedade a partir do financiamento à expansão de atividades e serviços demandados pelo cidadão e do reconhecimento desse pela população.

Diante das demandas endereçadas ao sistema político, os governos estão cada vez mais sensibilizados a aumentar os canais de participação social na governança, que se tornaram rótulos para que se tenha um "bom governo" pela sua perspectiva democrática (TORRES, 2016).

Assim, governança e governabilidade caminham ao lado da noção de imagem pública, pois é "na sedimentação ou na fragilidade da opinião, em relação ao sujeito político, [que] reside a credibilidade deste, construída pela sua capacidade de ratificar, publicamente, o acordo em torno de verdades e projetos" (WEBER, 2004, p. 261). A construção da imagem pública é, contudo, um processo complexo que passa por diversas etapas, a saber: as ações de instituições e sujeitos políticos, informações de interesse público, a participação midiática e a repercussão pública.

Se por um lado a imagem pública se alicerça nas ações e fatos, considerando esses últimos elementos como parte da governabilidade enquanto execução de governo, por outro, McNair (2015) destaca que o poder político ou a autoridade para governar resultam, ao menos em parte, de imagens e símbolos, e políticos de sucesso desenvolvem imagens que ecoam naqueles que desejam influenciar ou governar.

Nessa articulação de discursos e práticas sociais ocorre a política de imagem, ou seja, o "fenômeno da transformação da arena política num espaço de competição pela produção de imagens dos atores políticos, pelo controle do modo de sua circulação na esfera de visibilidade pública, pelo seu gerenciamento nos media e pela sua conversão em imagem pública" (GOMES, 2004, p. 37).

Considerando o marketing político, destaca-se como especificidade da área "o esforço planejado para se cultivar a atenção, o interesse e a preferência de um mercado de eleitores" (DO REGO, 1985, p. 84) e que a estratégia é o primeiro passo para o seu planejamento. Assim, concorda-se com a perspectiva de que resta no campo da produção da imagem pública política pouco espaço para o acaso, consolidando a avaliação de que grande parte dos movimentos foram antes minimamente delineados com o objetivo de se produzir uma imagem favorável. 
De fato, o marketing político ocupa um espaço localizado na interface entre a política e a comunicação (GOMES, 2004), e age como um instrumento para a comunicação política, tendo o discurso como um de seus elementos-chave. O discurso, ou espaço da fala, como denominado por Foucault (1996), torna-se não apenas o instrumento pelo qual o poder é exercido, e sim aquilo pelo que se luta.

É nesse ambiente de conflitos e acomodações em torno do poder que a comunicação e o discurso emergem como instrumentos unificadores de dois planos pelos quais a imagem pública é construída, o plano concreto e palpável, ligado aos aspectos físicos daquilo que uma sociedade anseia e o aspecto simbólico, que contém matérias primas psicológicas e intangíveis (GALICIA, 2010). Longe de se colocar como verdade uníssona, o discurso político se estabelece como jogo de versões nas disputas que marcam o sistema eleitoral competitivo e os dividendos do processo. Ele é elaborado do conhecimento e análise dos componentes do cenário estratégico de atuação. Assim, o próximo capítulo apresenta a metodologia aplicada para analisar os discursos de Michel Temer.

\section{Métodos}

Traçam-se como objetivos desse trabalho analisar quanto e como os dois discursos proferidos por Michel Temer se aproximam e se distanciam. Nesse sentido, visando investigar quais as semelhanças e particularidades existentes e quais os elementos retóricos empregados, optou-se pela aplicação da proposta de Panke e Cervi (2011) amparada na Análise de Conteúdo (BARDIN, 1977). Embora a metodologia tenha um enfoque em programas eleitorais, percebeu-se a potencialidade na aplicação em outros tipos de discursos políticos, como é o caso dos discursos de Michel Temer.

Como se trata de uma pesquisa que obedece a critérios de análises quantitativas descritivas e qualitativas no exame de um objeto empírico complexo, concorda-se que "essa união de diferentes abordagens metodológicas permite um aprofundamento das conclusões que não é possível quando se opta por apenas um dos conjuntos de técnicas aplicadas à Análise de Conteúdos" (PANKE; CERVI, 2011, p. 391). 
A fim de viabilizar esta análise, a coleta dos discursos ocorreu a partir dos vídeos disponíveis no Canal Panke $(2017)^{6}$. Com isso, realizou-se a transcrição do discurso vazado em 11 de abril de 2016 e utilizou-se a transcrição oficial do discurso de posse de 12 de maio de 2016 (PLANALTO, 2017). A partir daí os discursos foram segmentados em frases e, para verificar a primeira hipótese, aplicou-se a Análise de Conteúdo (AC), método que possui potencial híbrido cuja aplicabilidade pode ocorrer em caráter quantitativo descritivo e qualitativo. Tal definição se embasa em seu potencial em detectar as tendências e as categorizações temáticas dentro de um texto.

Com isso, foi possível elencar, quantificar e descrever a presença de assuntos divididos em categorias temáticas, conforme seguem:

1) Administração pública: propostas para gerir o país; promessas de melhorias; prestação de contas; políticas fiscais e monetárias; (des) emprego; índices econômicos (inflação, PIB, reformas, etc.);

2) Michel Temer: Michel Temer como protagonista; autoelogios; biografia; carreira política; vida pessoal;

3) Política institucional: Estado, governo; partidos; instituições públicas e agentes envolvidos; relação com os Três Poderes (Executivo, Legislativo e Judiciário); Estado Democrático de Direito; fatos ligados à governabilidade;

4) País: referências às características do país e do seu povo;

5) Desqualificação: desqualificação a governos anteriores, a outro grupo político/partido ou à situação do país;

7) Esportes, lazer e cultura: ações relativas à área cultural e entretenimento; programas para a juventude, terceira idade e crianças; grandes eventos (jogos olímpicos, shows, concertos, exposições de arte, peças de teatro etc.);

8) Lideranças: referências positivas a pessoas públicas (políticos, juízes, artistas etc.) e a governos anteriores;

9) Político-sociais: desenvolvimento social; programas sociais; inclusão social; temas relacionados à desigualdade social, assistência social;

10) Religião: liberdade religiosa; Deus, religiões (católica, evangélicos etc.).

6 Disponível em: <https://www.youtube.com/user/ocanalpanke>. Acesso em: 18 abr. 2017. 
Vale destacar que as categorias servem como tipos ideais no sentido weberiano, ou seja, não se encontram em sua forma pura. Portanto, categorizaram-se as frases de acordo com sua majoritariedade temática para "criar conceitos úteis para finalidades especiais e para orientação" (WEBER, 1974, p. 345). Logo, realizou-se uma adaptação das categorias propostas por Panke e Cervi (2011) a partir da leitura do corpus de modo que se consideraram somente as categorias que de fato apareceram nos discursos.

Após a classificação temática, buscou-se compreender não apenas o que foi falado, mas o modo pelo qual se trataram os temas a partir da hipótese de que os recursos retóricos utilizados para construção dos discursos variaram conforme a conjuntura. Esse viés é fundamental para verificação de trechos discursivos que se repetem entre os discursos ou que encadeiam relações muito próximas aos contextos políticos analisados. Não obstante, para operacionalizar esta etapa, buscou-se avaliar trechos por meio da Nova Retórica, de Perelman e Olbrechts-Tyteca (2014), autores que resgatam a retórica como instrumento de análise.

Ao tratar com auditórios, entendem como "o conjunto daqueles que o orador quer influenciar com sua argumentação" (PERELMAN; OLBRECHTS-TYTECA, 2014, p. 22). Há, contudo, uma distinção entre um auditório universal e os particulares. Se por um lado a argumentação para o convencimento trabalha a razão e a adesão de todo o ser racional (universal), a persuasão, por outro, vale-se de aspectos emocionais e se direciona a auditórios particulares.

Além de argumentar, é necessário ser escutado, estimar a adesão do interlocutor, seu consentimento e participação mental por meio de acordos, pois "não há argumentação possível sem algum acordo prévio entre o orador e seu auditório" (REBOUL, 2004, p. 164). A retórica é, portanto, o meio que possibilita o orador persuadir e/ou convencer seus auditórios partindo de acordos prévios (PERELMAN; OLBRECHTS-TYTECA, 2014). Nesse sentido, há um rol de técnicas argumentativas para a construção de discursos, pois o simples fato de "selecionar certos elementos e de apresentá-los ao auditório já implica a importância e a pertinência deles no debate" (PERELMAN; OLBRECHTS-TYTECA, 2014, p. 132).

Os autores propõem uma classificação das técnicas em duas macrocategorias que "visam apontar como o discurso encadeia as táticas de 
convencimento ou persuasão" (PANKE; CERVI, 2011, p. 400), a saber: argumentos por ligação e por dissociação. Enquanto esses são "técnicas de ruptura com o objetivo de dissociar, de separar, de desunir elementos considerados um todo" (PERELMAN; OLBRECHTS-TYTECA, p. 2014, 215), aqueles são classificados em argumentos quase-lógicos; baseados na estrutura do real; e que fundamentam a estrutura do real. $\mathrm{O}$ quadro abaixo (QUADRO 1) ilustra e apresenta a variedade de argumentos apresentados e descritos em Perelman e Olbrecths-Tyteca (2014).

\section{Quadro 1: Tipologia Argumentativa}

\begin{tabular}{|c|c|c|}
\hline \multirow{5}{*}{$\begin{array}{l}\text { Argumentos por } \\
\text { ligação }\end{array}$} & $\begin{array}{l}\text { Argumentos quase-lógi- } \\
\text { cos }\end{array}$ & $\begin{array}{l}\text { Contradição e incompatibili- } \\
\text { dade; o ridículo; identidade e } \\
\text { definição; analiticidade, aná- } \\
\text { lise e tautologia; a regra de } \\
\text { justiça; reciprocidade; tran- } \\
\text { sitividade; inclusão da parte } \\
\text { no todo; divisão do todo em } \\
\text { partes; comparação; argu- } \\
\text { mentação pelo sacrifício; } \\
\text { probabilidades. }\end{array}$ \\
\hline & & $\begin{array}{l}\text { Ligações de sucessão: } \\
\text { vínculo causal; argumen- } \\
\text { to pragmático; os fins e os } \\
\text { meios; do desperdício; da } \\
\text { direção; de superação. }\end{array}$ \\
\hline & $\begin{array}{l}\text { Argumentos baseados na } \\
\text { estrutura do real }\end{array}$ & $\begin{array}{l}\text { Ligações de coexistência: a } \\
\text { pessoa e seus atos; intera- } \\
\text { ção entre o ato e a pessoa; } \\
\text { de autoridade; técnicas de } \\
\text { ruptura e refreamento opos- } \\
\text { tas à interação ato-pessoa; } \\
\text { discurso como ato do ora- } \\
\text { dor; grupo e seus membros; } \\
\text { ato e a essência; ligação } \\
\text { simbólica; hierarquia dupla; } \\
\text { diferenças de grau e de or- } \\
\text { dem. }\end{array}$ \\
\hline & $\begin{array}{l}\text { Argumentos que funda- } \\
\text { mentam a estrutura do real }\end{array}$ & $\begin{array}{l}\text { Casos particulares: pelo } \\
\text { exemplo; ilustração; mode- } \\
\text { lo e antimodelo; ser perfeito } \\
\text { como modelo }\end{array}$ \\
\hline & & Analogia: metáfora \\
\hline
\end{tabular}




\begin{tabular}{|l|l|l|}
\hline $\begin{array}{l}\text { Argumentos por } \\
\text { dissociação }\end{array}$ & $\begin{array}{l}\text { Ruptura de ligação e disso- } \\
\text { ciação; "aparência-realida- } \\
\text { de"; pares filosóficos. }\end{array}$ \\
\hline
\end{tabular}

Fonte: Adaptado de Perelman e Olbrechts-Tyteca (2014).

A argumentação quase-lógica se desenvolve com base em esquemas formais e dados concretos, referenciando a uma realidade e, comparáveis a raciocínios aparentemente incontestáveis, possuem força de convencimento. (PERELMAN; OLBRECHTS-TYTECA, 2014). São eles: contradição e incompatibilidade; o ridículo; identidade e definição; analiticidade, análise e tautologia; a regra de justiça; reciprocidade; transitividade; inclusão da parte no todo; divisão do todo em partes; comparação; argumentação pelo sacrifício; probabilidades.

Ao que tange os baseados na estrutura da realidade, o orador remete a valores e emoções e a forma de apresentação é mais importante do que os próprios dados. São as ligações de sucessão e de coexistência. Por fim, os que fundamentam a estrutura do real são arrolados em casos particulares e uso da analogia (PERELMAN; OLBRECHTS-TYTECA, 2014). Isso posto, a seção seguinte apresenta e discute os resultados encontrados.

\section{Resultados}

A partir da aplicação metodológica, obteve-se uma classificação de 87 frases no discurso vazado e 139 no oficial. Com a Análise de Conteúdo, verificou-se que a variação temática representa 28,6\% do total analisado em valor absoluto. Isso significa que há um padrão temático de 71,4\% entre ambos os discursos, o que confirma a hipótese de que o áudio do WhatsApp pode ser interpretado como uma prévia do discurso de posse.

As temáticas mais utilizadas em ambos foram "Político institucional" e "Administração pública", com presença na casa dos 40\% e 30\%, respectivamente (Figura 1). Enquanto a primeira teve ênfase por parte do emedebista, recebendo um acréscimo de 4,7\% em espaço no discurso 
de posse em relação ao vazado, a segunda recebeu maior apelo quando Temer ainda ocupava a Vice-Presidência, representando 35,6\% do total para este discurso.

Figura 1: Categorias nos discursos de Michel Temer (\%).

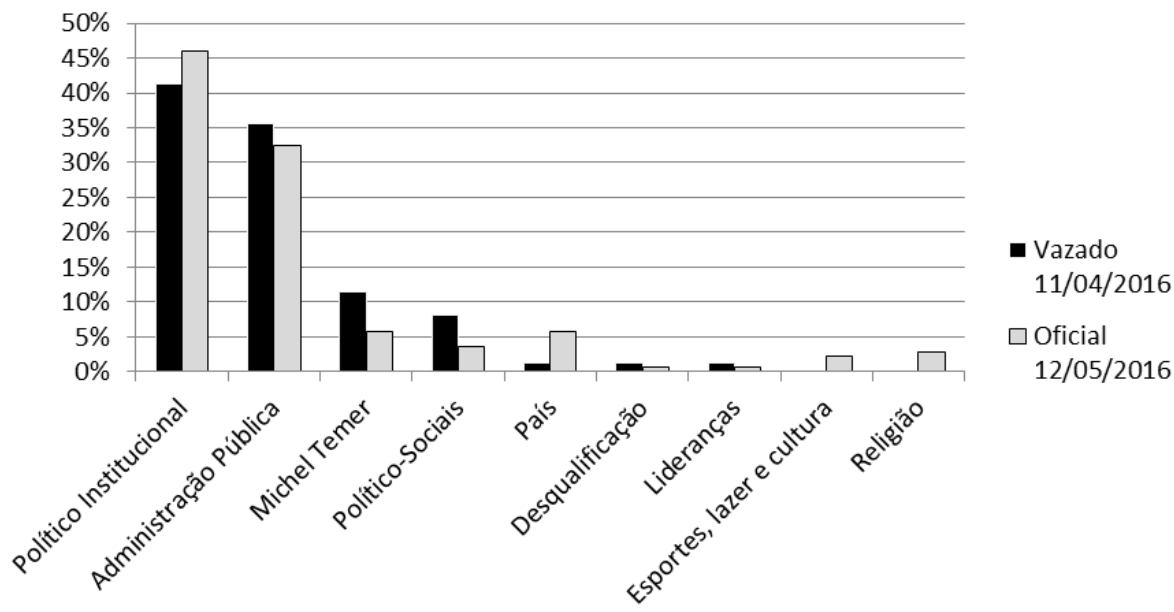

Fonte: Os autores (2017).

Os temas diretamente ligados à imagem do presidente (categoria Michel Temer) aparecem em terceiro lugar. A principal característica se relaciona à maior diferença entre os discursos dentre todas as categorias levantadas, beirando os 6\%. Uma explicação para tal fato reside na ideia de que, diante de uma conjuntura política turbulenta em vias do processo de impeachment, Temer tenderia a expor sua imagem como o sucessor constitucional à Presidência.

"Político-sociais" e "País" foram as categorias que receberam, ao menos em um dos discursos, 5\% ou mais. Quanto à primeira, verifica-se a queda na casa dos $4 \%$ em relação ao discurso oficial. A categoria "País" corresponde à terceira maior diferença percentual ao longo do tempo, com 4,4\% de utilização a mais no discurso oficial. Dessa forma, Temer valorizou potencialidades e características do país, evitando enfatizar temas que poderiam resultar em controvérsias, tendo em vista as almejadas reformas.

Em seguida, a fim de compreender como os temas mais relevantes foram colocados por Temer em seus discursos, passou-se à análise 
qualitativa das principais categorias. A repetição de fragmentos na categoria "Político institucional" entre os dois discursos é apresentada, se não exatamente da mesma forma, minimamente alterada. A afirmação de que "o Estado não pode tudo fazer" (TEMER, 2016a, p. 3; TEMER, 2016b, p. 1) é seguida de suas competências, no caso, "cuidar da segurança, da saúde, da educação, enfim, de alguns temas fundamentais que não podem sair da órbita pública" (ibidem).

Conceitos como governança e governabilidade (TEMER, 2016a, p. 3-4; TEMER, 2016b, p. 2), a proposta de um governo de salvação nacional (TEMER, 2016a, p. 2; TEMER, 2016b, p. 1) e a necessidade de uma federação real (TEMER, 2016a, p. 4; TEMER, 2016b, p. 2) também se repetem. Isso coaduna-se com a noção que Figueiredo et al. (2000) trazem de o político mostrar ao público que o copo está meio cheio ou meio vazio. Assim, Michel Temer busca persuadir seu auditório de que é possível melhorar a situação por meio de mudanças pontuais.

Vale destacar o uso de ligações de sucessão no discurso oficial, argumentos baseados na estrutura do real, que "utilizam o conhecimento empírico do orador e do auditório para provocar a anuência" (PANKE, 2010, p. 51). Embora parta de argumentos semelhantes, uma espécie de antecipação à governabilidade, o discurso oficial apresenta desdobramentos desses argumentos em objetivos de governo. Assim, de uma forma oblíqua, o discurso vazado funciona como uma plataforma de marketing para a governabilidade, o que na segunda etapa discursiva se detalha com Temer se apresentando como presidente, exibindo linhas previamente delineadas na exposição de seu primeiro discurso. O seguinte trecho ilustra a argumentação por vínculo causal:

Nós precisamos atingir aquilo que eu chamo de "democracia da eficiência”. Porque se, no passado, nós tivemos, por força da Constituição, um período da democracia liberal [...]. Se, ao depois, ainda ancorado na Constituição, nós tivemos o desfrute dos chamados direitos sociais, que são previstos na Constituição, num dado momento aqueles que ascenderam ao primeiro patamar da classe média, começaram a exigir eficiência, eficiência do serviço público e eficiência nos serviços privados. E é por isso que hoje nós estamos na fase da democracia da eficiência [...]. (TEMER, 2016b, p. 3)

A "democracia da eficiência" é trazida como resultado de uma evolução histórica e constitucional. Borges (2001, p. 160) reflete sobre a 
tensão entre democracia e eficiência do Estado que poderia ser resolvida com "a defesa de um Estado liberal capaz de abrir espaço para o livre mercado limitando sua intervenção ao mínimo necessário". De fato, a ideia de um Estado liberal coaduna-se com o documento "Uma ponte para o futuro", lançado pelo PMDB ainda em 2015 (PMDB, 2015).

As ligações de sucessão "tendem a relacionar dois acontecimentos sucessivos dados entre eles por meio de um vínculo causal" (PERELMAN; OLBRECHTS-TYTECA, 2014, p. 299). Em outras palavras, a ideia de Temer é um Estado liberal cujas mudanças estariam vinculadas a uma evolução da sociedade e pautadas em demandas populares. Grosso modo, o povo clamaria por eficiência e o governo interino estaria em uma situação de transição apresentando a agenda de governo na cena pública.

Na categoria "Administração pública" também há a presença de trechos e técnicas semelhantes, caso da identidade e definição (quase-lógica) que "indica a forma em que se quer que uma palavra seja utilizada" (PERELMAN; OLBRECHTS-TYTECA, 2014, p. 239). Ao classificar a iniciativa privada como a "conjugação da ação entre empregadores e trabalhadores" (TEMER, 2016a, p. 3; TEMER, 2016b, p. 1), o orador direciona sua fala a um auditório universal fazendo com que "semelhante juízo imponha-se a todos, porque o próprio orador está convencido de que ele não poderia ser posto em dúvida" (PERELMAN; OLBRECHTS-TYTECA, 2014, p. 35-36).

Observa-se no primeiro discurso que Temer recorre a argumentos quase-lógicos de sacrifício ao apresentar a necessidade de reformas. Isso demonstra um redirecionamento de governabilidade como resposta ao contexto de polarização e crise no país. Isso representa "o sacrifício a que está disposto a sujeitar-se para obter certo resultado" (PERELMAN; OLBRECHTS-TYTECA, 2014, p. 281), conforme seguinte trecho:

E neste particular, nós pretendemos fazer várias reformas que incentivem a essa harmonia entre esses dois setores da produção brasileira. Tudo isso que estou a dizer significará, devo registrar, sacrifícios iniciais para o povo brasileiro, em primeiro lugar. (TEMER, 2016a, p. 3)

Essa necessidade é amenizada no discurso oficial como algo que aconteceria ao longo do tempo e garantiria o pagamento de aposentadorias e a geração de empregos. O uso de argumentos de fins e meios 
(baseados na estrutura do real) parece útil, pois "a escolha de certo fim permite valorizar uma ação que, noutras situações, costuma-se condenar" (PERELMAN; OLBRECHTS-TYTECA, 2014, p. 315).

Ao afirmar que "a modificação que queremos fazer, tem como objetivo, e só se este objetivo for cumprido é que elas serão levadas adiante, mas tem como objetivo o pagamento das aposentadorias e a geração de emprego" (TEMER, 2016, p. 2), Temer enfatiza a finalidade das reformas e ofusca o meio utilizado para chegar ao seu objetivo. Conforme explica Panke (2010), a noção de sujeito é fundamental visto que era o vice-presidente num contexto hipotético. Contudo, ao proferir o discurso de posse, o presidente passa a necessitar apoio popular evitando medidas impopulares.

Ao dizer "quando me pedirem para fazer alguma coisa, eu farei como Dutra, o que é que diz o livrinho? " (TEMER, 2016b, p. 2), no discurso de posse, Temer apresenta-se numa base democrática e jurídica ao levantar a figura do ex-presidente Gaspar Dutra e da Constituição, chamada de livrinho, dando a ideia de intimidade(COELHO NETO, 2013). Tanto é que esta pergunta retórica se associa diretamente à resposta dada na frase seguinte, a saber, "o livrinho é a Constituição Federal" (TEMER, 2016b, p. 2).

Esse é o argumento de autoridade (baseados na estrutura do real), pois "quem arrazoa contenta-se em enumerar as autoridades nas quais se pode confiar ou indicar aquelas às quais se concederá a preferência em caso de conflito" (PERELMAN; OLBRECHTS-TYTECA, 2014, p. 350), colocando em paralelo o baseado na competência, trazendo a Constituição, ou o próprio Dutra, como árbitros do comportamento.

\section{Considerações finais}

Com base nos resultados encontrados, é possível inferir que os discursos que Temer proferiu em meio ao processo de impeachment de Dilma Rousseff auxiliaram na pavimentação do caminho para um governo de transição. O primeiro discurso veio à tona por meio do vazamento de um áudio, quando ainda era vice-presidente e contribuiu com o clima de espetacularização política. Já o segundo discurso foi proferido na posse como presidente interino, após a confirmação do afastamento, 
e apresentou similaridades com o anterior recorrendo a expressões e temáticas semelhantes.

Por meio da Análise de Conteúdo, verificou-se um padrão temático de $71,4 \%$ entre os discursos e que as temáticas mais utilizadas em ambos os discursos foram "Político institucional" e "Administração pública". Não obstante, percebe-se que, além deste padrão, diversos assuntos em ambos os discursos são os mesmos. O discurso oficial se acomodou e apresentou efetivamente o plano de governabilidade, com convocação de apoio do Congresso - em uma perspectiva de reordenamento institucional -, e as bases para medidas econômicas. Tais indícios permitem confirmar que o discurso vazado foi uma prévia do cerne de assuntos que o segundo discurso detalhou.

A aplicação qualitativa permitiu verificar como Temer desenvolveu os argumentos em ambos os discursos e a confirmar a hipótese de que houve variações nos apelos retóricos (técnicas argumentativas). Dessa forma, em um contexto de alta polarização política, há aspectos estratégicos de persuasão para a possibilidade de sua governabilidade que colocam Temer como um político credenciado para o cargo de presidente. $E$ isso muda num segundo momento no detalhamento de propostas quando se torna presidente, em um contexto em que busca unir Congresso, Planalto e população.

Considerando o aspecto simbólico, os dados permitem algumas interpretações contextuais que indicam entendimentos para um suposto marketing para a governabilidade forjado por Michel Temer entre os dois discursos. A construção discursiva a partir da priorização às categorias "Político institucional" e "Administração pública" tiveram um viés coletivo nacional que visava drenar a polarização Congresso x Planalto e a estabilização política no momento.

Portanto, foram apresentadas as condições de um acordo proposto como uma espécie de candidato a presidente interino, delineando uma agenda de governo, apropriando-se do universo de espetacularização informacional e midiática a partir da repercussão de notícias políticas ao utilizar o áudio de forma estratégica.

Vale frisar que esta pesquisa não parte do pressuposto de que o áudio de Temer foi vazado de forma proposital. Porém, as evidências apresentadas permitem avaliar que, uma vez vazado, o áudio acabou sendo utilizado como uma estratégia de marketing político, uma espécie de balão de ensaio, ao delinear os argumentos e temas que deveriam 
ou não ser utilizados no discurso de posse e como forma de testá-los na cena pública.

\section{REFERÊNCIAS}

ALMEIDA, Adjovanes Thadeu S. de, LIMA, Vitória T. L. da Silva. Dilma Rousseff Na Imprensa Brasileira: Da Reeleição Ao Processo De Impeachment. Revista Encontros, v. 14, n. 26, 2016.

BARDIN, Laurence. Análise de conteúdo. Lisboa: Edições 70, 1977.

BORGES, André. Democracia vs. eficiência: a teoria da escolha pública. Lua Nova, São Paulo, n. 53, 2001.

BRAGA, Sérgio, MONTROSE, Edilson. Do questionamento da política econômica do governo Dilma à campanha pelo "Impeachment Já": a ação política das frações empresariais brasileiras nas mídias sociais na conjuntura recente. In: NAPOLITANO, C. J., VICENTE, M. M., SOARES, M. C. (org.) Comunicação e cidadania política. São Paulo: Cultura Acadêmica, 2017.

COELHO NETO, Ubirajara. Temas de Direito Constitucional: estudos em homenagem ao Profo. Carlos Rebelo Junior. Aracaju: EVOCATI, 2013.

COIMBRA, Mayra Regina. A construção da imagem de Dilma Rousseff e de seu governo: uma análise dos pronunciamentos políticos na semana de votação do Impeachment no Senado. Sociedade Brasileira de Estudos Interdisciplinares da Comunicação, XXII Intercom Sudeste, 2017.

DO REGO, Francisco G. Torquato. Marketing Político e governamental um roteiro para campanhas políticas e estratégias de comunicação. Summus Editorial, 1985.

DUARTE, Luiz Fernando Dias. Valores cívicos e morais em jogo na Câmara dos Deputados: a votação sobre o pedido de impeachment da Presidente da República. Religião \& Sociedade, 37(1), 145-166, 2017. DOI: 10.1590/0100-85872017v37n1cap08

FIGUEIREDO, Marcus. et. al. Estratégias de Persuasão em Eleições Majoritárias: Uma Proposta Metodológica para o Estudo da Propaganda Política. In: FIGUEIREDO, A. Marketing Político e Persuasão Eleitoral. São Paulo: Fundação Konrad Adenauer, 2000.

FOUCAULT, Michel. A Ordem do Discurso. 3. ed. São Paulo: Edições Loyola, 1996.

FREITAS, George, FRANÇA Hélder. Marketing político: uma análise do discurso durante o processo de admissão, pré e pós Impeachment de Dilma Rousseff no canal oficial do YouTube. Revista Temática, v. 13, n. 6, 2017.

GALICIA, Javier. S. Treinta claves para entender el poder. México: Piso 15, 2010.

GOMES, Wilson. Transformações da política na era da comunicação de massa. São Paulo: Paulus, 2004.

IACOMINI JUNIOR, Franco, CARDOSO, Moisés, PRADO JUNIOR, Tarcis. Os "nós" de Temer: uma análise dos discursos de posse de 2016. Revista Compolítica, v. 8, n. 1, 2018. DOl: https://doi. org/10.21878/compolitica.2018.8.1.139

MARQUES, Francisco P. J. M., MONT'ALVERNE, Camila, MITOZO, Isabele B. "Nem Dilma nem Temer": Um estudo quantitativo sobre padrões de cobertura do impeachment de Dilma Rousseff em editoriais jornalísticos. In: NAPOLITANO, C. J., VICENTE, M. M., SOARES, M. C. (org.) Comunicação 
e cidadania política. São Paulo: Cultura Acadêmica, 2017.

MCNAIR, Brian. Image, Political. In: Mazzoleni, G. (ed.) The International Encyclopedia of Political Communication. New Jersey: JohnWiley \& Sons, Inc, 2015.

NAPOLITANO, Carlos J. O Supremo Tribunal Federal na crise do impeachment: o diálogo com a sociedade civil. In: NAPOLITANO, C. J., VICENTE, M. M., SOARES, M. C. (org.) Comunicação e cidadania política. São Paulo: Cultura Acadêmica, 2017.

PANKE, Luciana, Cervi, Emerson U. Análise da Comunicação Eleitoral: uma proposta metodológica para os estudos de HGPE. Revista Contemporânea. V. 9. N. 3, 2011.

PANKE, Luciana. Lula, do sindicalismo à reeleição: um caso de comunicação, política e discurso. Guarapuava: Unicentro; São Paulo: Horizonte, 2010.

PERELMAN, Chaim, OLBRECHTS-Tyteca, Lucie. Tratado da argumentação: a nova retórica. São Paulo: Editora WMF Martins Fontes, 2014.

PLANALTO. Discurso do Presidente da República, Michel Temer, durante cerimônia de posse dos novos ministros de Estado Palácio do Planalto. Portal Planalto. 2017. Disponível em: <https://goo. gl/ZRu2CC>. Acesso em: 20 abr. 2017.

PMDB. Uma Ponte para o Futuro. Fundação Ulysses Guimarães, 2015.

REBOUL, Oliver. Introdução à Retórica. São Paulo: Martins Fontes, 2004.

TEMER, Michel. Ensaio de discurso vazado pelo WhatsApp em 11 de abril de 2016. 2016a. Disponivel em: <https://goo.gl/YYDRNI>. Acesso em: 17 abr. 2017.

TEMER, Michel. Discurso proferido em ocasião da posse de Michel Temer como Presidente interino no dia 12 de maio de 2016. 2016b. Disponível em: <https://goo.gl/fK6I85>. Acesso em: 17 abr. 2017.

TOMÉ, Vitor. O jornalismo pós-Snowden em contextos de aceleração social. In: MOREIRA, A.; ARAÚJO, E., SOUSA, H. (Eds). Comunicação e Política: Tempos, Contextos e Desafios. Centro de Estudos de Comunicação e Sociedade, Universidade do Minho, Braga, Portugal, 2017.

TORRES, Roberto D. Governabilidade, governança e poder informal. Civitas, Porto Alegre, v. 16, n. 1, p. 153-171, 2016.

WASHINGTON-NICHOLS, Bruno, CHAPAVAL-PIMENTEL, Pedro. Impeachment e imagem pública: uma análise do discurso vazado de Michel Temer. Revista Internacional de Relaciones Públicas, V. VII, N. 13, 2017. DOI: 10.5783/RIRP-13- 2017-04-41-60.

WEBER, Max. Ensaios de sociologia. 3. Ed. Rio de Janeiro: Zahar Editores, 1974.

WEBER, Maria Helena. Imagem Pública. In: Rubim, A. Comunicação e Política, conceitos e abordagens. Salvador: Editora UFBA, 2004. 




